\title{
PENGUKURAN RADIOAKTIVITAS GAMMA PADA SAMPEL TANAH DI DAERAH KABUPATEN MAMUJU
}

\author{
Dzulqadri Imran ${ }^{1}$, Iswadi ${ }^{1}$, Sri Zelviani ${ }^{1}$, dan Elisabeth Supriyatni ${ }^{2}$ \\ 1Jurusan Fisika Fakultas Sains dan Teknologi, UIN Alauddin Makassar \\ ${ }^{2}$ Pusat Sains dan Teknologi Akselerator - Badan Tenaga Nuklir Nasional \\ Email: dzulqadri.physics@gmail.com,wadi.phys.uin@gmail.com, \\ sri.zelviani@uin-alauddin.ac.id
}

\begin{abstract}
The research aims to determine the level of radioactivity in the district of Mamuju and compare it with other land activities. and prove previous research on land activity in Mamuju is quite high. Measurements are done using the method of counting and identifying. That is identifying the radionuclides contained in the sample according to the Uranium and Thorium series. The tools used are LBC (Low Background Counter) and Gamma spectrometry. The results showed that: land activity in all samples has exceeded the limits established by PERKA BAPETEN and IAEA (International of Atomic Agency). The highest radioactivity results are found in the Takandeang region. And on all three samples showed the results of a very significant natural radionulida activity on vulnerable concentrations of activity in European countries.
\end{abstract}

Keywords: radioactivity, land, regency of Mamuju

\section{PENDAHULUAN}

Radiasi pengion berada dimanapun di dunia dan hampir tidak ada satupun yang tidak mengandung unsur radioaktif. Telah diketahui bahwa setiap hari manusia selalu terpapar radiasi alam baik radiasi kosmik, radiasi terestrial yang terutama dari radionuklida primordial di kerak bumi yaitu uranium dan throrium beserta luruhannya.

Naturally Occuring Radioactive Material (NORM) merupakan sumber radiasi alam yang terjadinya bersamaan dengan terciptanya alam semesta. NORM akan ditemukan disemua tempat di dunia dengan tingkat konsentrasi yang berbeda-beda. Sumber radiasi NORM dipengaruhi oleh keberadaan batuan dari deret Uranium ataupun deret Thorium di suatu tempat. Karena berasal dari alam, keberadaan sumber radiasi ini tidak dapat dihindari, namun dapat dikendalikan potensi bahayanya. IAEA menganggap fenomona alam tersebut sebagai sumber radiasi existing (exixting exposure).

Dari peta laju dosis radiasi lingkungan yang dibuat berdasarkan hasil survei yang dilakukan Pusat Teknologi Keselamatan dan Metrologi Radasi (PTKMR), BATAN sampai tahun 2010, diketahui bahwa di Indonesia terdapat beberapa daerah yang mempunyai radiasi latar alam yang lebih tinggi dari daerah lain, diantaranya adalah Kabupaten Mamuju di Sulawesi Barat. Pengukuran yang dilakukan antara lain pengukuran eksternal terhadap tingkat paparan radiasi gamma. Tingkat paparan 
radiasi gamma rerata di Kabupaten Mamuju sebesar 0,631 \pm 0,569 $\mu$ Sv/jam , sedangkan tingkat laju dosis radiasi total eksternal rerata di Indonesia adalah 0,067 $\mu \mathrm{Sv} / \mathrm{jam}$. Pengukuran radiasi gamma di lingkungan dilakukan secara langsung menggunakan mobil yang dilengkapi dengan porTabel gamma ray spectrometer (surveimeter Exploranium Model GR-130),dan Global Positioning System (GPS) pada grid $30 \mathrm{~km} \times 30 \mathrm{~km}$.

Penelitian tentang radioaktivitas di Mamuju juga pernah dilakukan oleh Moekhammad Alfiyan dengan melakukan pengukuran di seluruh wilayah Kabupaten Mamuju. Pengukuran laju paparan eksternal dilakukan dengan metode airborne, menggunakan 2 (dua) buah peralatan Radeye, dengan nomor seri Radeye PRD/SN.3102 dan Radeye PRD/SN.3156. Pengukuran lebih mendalam dilakukan di daerah-daerah yang tingkat radiasinya dianggap paling signifikan. Pengukuran laju dosis gamma menggunakan alat ukur RadEye PRD di sepanjang jalan yang dilewati. Hasil pengukuran paparan radiasi menunjukkan tingkat radiasi alam di kabupaten Mamuju pada rentang $0,20 \mu \mathrm{Sv} / \mathrm{jam}$ sampai dengan 2,84 $\mu \mathrm{Sv} / \mathrm{jam}$, sedangkan nilai rata-rata dunia adalah $0,08 \mu \mathrm{Sv} / \mathrm{jam}$. Tingkat radiasi yang signifikan ditemukan di Desa Botteng dan Desa Takandeang. Hasil analisis sampel tanah menunjukan konsentrasi aktivitas Th-232 teritinggi sebesar 2,909 $\pm 0,273 \mathrm{~Bq} / \mathrm{gram}$. Konsentrasi radon di beberapa rumah penduduk melampaui nilai reference level sebesar 300 $\mathrm{Bq} / \mathrm{m}^{3}$. Tingkat radiasi alam NORM di Kabupaten Mamuju disebabkan oleh kondisi geologi kabupaten Mamuju yang terletak dalam formasi gunung api adang dengan luas $820 \mathrm{~km}^{2}$.

\section{METODE PENELITIAN}

Penelitian ini menggunakan dua alat yang berbeda. Yaitu dengan menggunakan alat cacah latar rendah (LBC) dan Spektrometri Gamma. Serta identifikasi secara manual untuk mengetahui induk dari anak luruh radionuklida yang terdeteksi pada alat.

Pengambilan sampel dilakukan secara langsung di tiga kecamatan berbeda di Kabupaten Mamuju.sampel kemudian untuk preparasi sampel dilakukan di laboratotium preparasi PSTA-BATAN. Sampel dikeringkan selama 3-4 hari sampai benar-benar kering, kemudian dibersihkan dari akar tanaman dan daun pada sampel, kemudian sampel dimasukkan ke dalam ballmill untuk dihaluskan dan diayak dengan ayakan 200 mesh. Setelah preparasi sampel selesai, maka sampel yang telah diayak dimasukkan ke dalam vial plastik untuk dimasukkan ke dalam kamar detektor spektrometri gamma. Dan diatur wajtunya selama 12 jam.Sedangkan untuk LBC, sampel yang telah digerus dan diayak dimasukkan ke dalam planset dan ditimbang dalam neraca analitik hingga berat sampel mencapai 1 gram.setelah ditimbang, sampel kemudian distabilkan dengan menggunakan air suling (Aquades) dan dikeringkan di atas hotpale hingga sampel mengering. Dan dimasukkan ke dalam kamar detector LBC dan dicacah. Sebelum sampel dicacah ke dalam alat, terlebih dahulu planset kosong dimasukkan ke dalam detector lbc untuk diukur cacah latarnya selama 30 menit. Sampel dicacah selama 30 menit.

Sebelum melakukan perhitungan aktivitas dengan menggunakan alat lbc, terlebih dahulu ditentukan efisiensi alat LBC dengan menggunakan sumber standar $\mathrm{K}-40$ dari $\mathrm{KCl}$ dengan menggunakan rumus : 


$$
\text { Effisiensi }=\frac{\text { cacah net persatuan waktu }}{\text { peluruhan } K-40 \text { per satuan waktu }} \times 100 \%
$$

Dan didapatkan hasil efisiensi alat lbc adalah 5,99\%. Untuk perhitungan aktivitas alat LBC setelah didapatkan hasil cacah latar dan cacah sampel nya maka aktivitas sampel dihitung dengan menggunakan rumus :

$$
\mathrm{A}=\frac{\mathrm{C} .100}{60 . \mathrm{W} \cdot \mathrm{Ef}} \mathrm{Bq} / \mathrm{gram}
$$

Sedangkan untuk perhitungan aktivitas tanah dengan menggunakan alat spektrometri gamma, setelah dicacah selama 12 jam maka akan diperoleh hasil radionuklida alam pemancar gamma yang terbaca dalam sampel. Sebelum melakukakn perhitungan aktivitas sampel, dilakukan kalibrasi energi dan kalibrasi efisiensi pada alat spektrometri gamma. Kalibrasi energi dilakukan dengan menggunakan aplikasi maestro-32 . dan untuk kalibrasi efisiensi dengan menggunakan sumber standar soil 6 . Dengan menggunakan rumus :

$$
\text { Efisiensi }=a \cdot\left(X^{b}\right)
$$

Rumus untuk menghitung aktivitas radionuklida adalah :

$$
\text { Aktivitas gamma }=\frac{\mathrm{Cps}}{\text { Ef.Yield.w }} \mathrm{Bq} / \mathrm{g}
$$

Dan untuk identifikasi radionuklida terkandung dalam sampel, identifikasi dilakukan dengan mengelompokkan radionuklida berdasarkan deret Thorium dan Uranium. Dan aktivitas masing-masing radionuklida dijumlahkan dan dirata-ratakan. Sebagai data pembanding maka diambil data dari aktivitas tanah di daerah Yogyakarta dan untuk aktivitas rata-rata sebagai data pembanding di ambil dari data konsentrasi radionuklida alam dalam tanah di negara lain oleh IAEA.

\section{HASIL DAN PEMBAHASAN}

\section{Hasil Perhitungan Aktivitas Tanah}

Tabel 1. Aktivitas tanah di Kabupaten Mamuju

\begin{tabular}{|c|c|c|c|c|c|c|c|}
\hline \multirow{2}{*}{ NO } & Lokasi & $\begin{array}{c}\text { Berat } \\
\text { Cuplikan } \\
\text { (gram ) }\end{array}$ & \multicolumn{2}{|c|}{ Laju Cacah ( CPM ) } & $\begin{array}{c}\text { Eff } \\
\text { (\%) }\end{array}$ & $\begin{array}{c}\text { Aktivitas } \\
\text { (Bq/gr) }\end{array}$ \\
\hline $\mathbf{1}$ & Takandeang & 1 & 47,49 & 2,22 & 45,27 & 5,99 & 12,59 \\
\hline
\end{tabular}




\begin{tabular}{|c|c|c|c|c|c|c|c|}
\hline $\mathbf{2}$ & Binanga & 1 & 12,84 & 2,22 & 10,62 & 5,99 & 2,96 \\
\hline $\mathbf{3}$ & Botteng 1 & 1 & 11,62 & 2,22 & 9,40 & 5,99 & 2,62 \\
\hline
\end{tabular}

Pada pengukuran aktivitas tanah menggunakan LBC dilakukan pengukuran sebanyak 3 sampel, 1 sampel diambil dari masing-masing titik lokasi yang berbeda yaitu 1 sampel di daerah Takandeang, 1 sampel di daerah takandeang dan 1 sampel di daerah Botteng. Dari tabel IV.1 hasil pengukuran diketahui bahwa aktivitas tertingi berada di daerah Takandeang dengan aktivitas tanah mencapai 12,59 Bq/gram. aktivitas tanah di Binanga ( Depan Rujab Bupati) mencapai 2,96 Bq/gram dan di daerah Botteng 1 aktivitas tanah mencapai 2,62 Bq/gram.

Tabel 2. Aktivitas tanah di Daerah Yogyakarta sebagai data pembanding

\begin{tabular}{|c|c|c|c|c|c|c|c|}
\hline \multirow{2}{*}{ NO } & \multirow{2}{*}{ Lokasi } & \multirow{2}{*}{$\begin{array}{c}\text { Berat } \\
\text { Cuplikan } \\
\text { (gram ) }\end{array}$} & \multicolumn{3}{|c|}{ Laju Cacah ( CPM ) } & \multirow{2}{*}{$\begin{array}{l}\text { Eff } \\
(\%)\end{array}$} & \multirow{2}{*}{$\begin{array}{c}\text { Aktivitas } \\
\text { (Bq/gr) }\end{array}$} \\
\hline & & & Cuplikan & Latar & Netto & & \\
\hline 1 & $\begin{array}{l}\text { Ut.Gd. } \\
\text { Bengkel }\end{array}$ & 1 & 3,87 & 2,73 & 1,13 & 5,99 & 0,32 \\
\hline 2 & $\begin{array}{l}\text { Timur } \\
\text { lapangan } \\
\text { tennis }\end{array}$ & 1 & 4,37 & 2,73 & 1,63 & 5,99 & 0,45 \\
\hline 3 & Kledokan & 1 & 4,27 & 2,73 & 1,53 & 5,99 & 0,43 \\
\hline
\end{tabular}

Jika dibandingkan dengan tabel 2 data hasil pengukuran aktivitas tanah di sekitar wilayah Yogyakarta oleh PSTA BATAN bulan Agustus 2018, aktivitas ratarata tanah normal tidak mencapai $1 \mathrm{~Bq} / \mathrm{gram}$. Hal ini menujukkan bahwa aktivitas tanah di daerah Mamuju memang menunjukkan aktivitas radionuklida alam yang cukup tinggi. dan untuk mengetahui penyebab tingginya aktivitas tanah tersebut, maka dilakukan pengukuran dengan spektrometri gamma pada sampel untuk mengetahui unsur radionuklida alam pemancar gamma yang terkandung pada sampel tersebut. 


\section{Spektrometri Gamma}

\section{AKTIVITAS TOTAL RATA-RATA NUKLIDA}

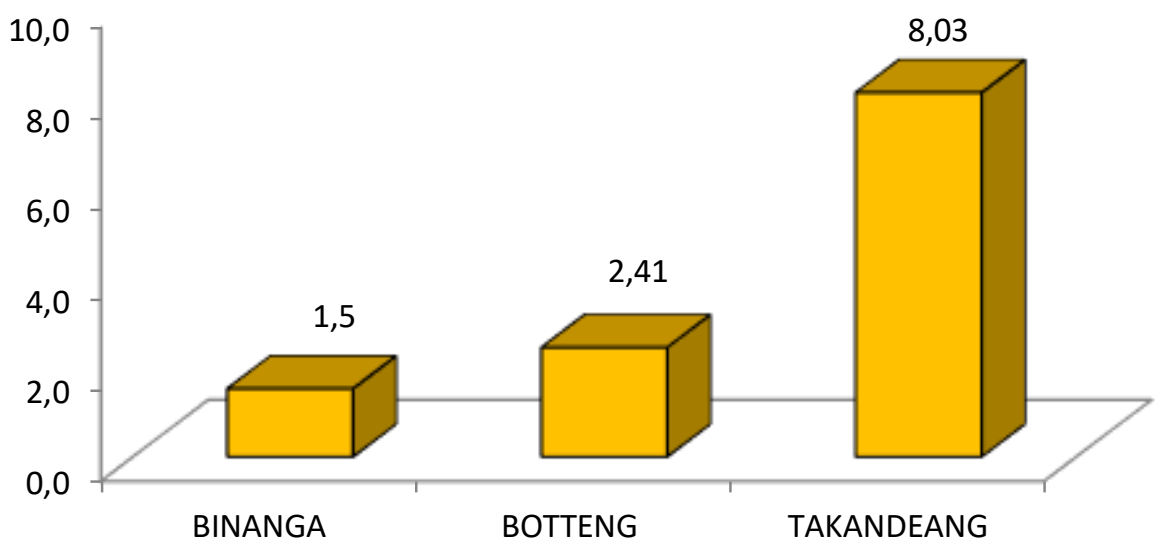

Gambar 1. Hasil perhitungan aktivitas gamma menggunakan spektrometri gamma.

Grafik diatas menunjukkan hasil pengukuran aktivitas rata-rata radionuklida pemancar gamma yang terkandung di daerah Takandeang, Botteng,dan Binanga dengan menggunakan alat spektrometri gamma. Jika kita membandingkan ketiga tabel hasil pengukuran aktivitas tanah yang ada pada grafik dapat diketahui bahwa pengukuran aktivitas tertinggi berada pada sampel tanah Takandeang dengan aktivitas total rata-rata sampel mencapai $8,034 \mathrm{~Bq} / \mathrm{g}$. Kemudian di daerah Botteng aktivitas nya mencapai 2,419 Bq/g.sedangkan untuk aktivitas tanah di daerah Binanga 1,455 Bq/g. Berdasarkan data BSS 115 Tahun 2011 yang diterbitkan oleh IAEA ( International Atomic Energy Agency), aktivitas tanah normal untuk deret Uranium dan Thorium adalah $1 \mathrm{~Bq} / \mathrm{g}$. Sedangkan k-40 batas aktivitas adalah 10 $\mathrm{Bq} / \mathrm{g}$. Dan jika melebihi batas itu, maka perlu diadakan pengawasan oleh pihak yang berwenang,dalam hal ini BAPETEN. Karena aktivitas total pada ketiga sampel melebihi batas yang ditetapkan oleh IAEA dan PERKA BAPETEN, maka sangat penting untuk dilakukan pengawasan lebih lanjut terhadap kawasan ini, baik terhadap penerima dosis maupun dampak-dampak lain. 


\section{Identifikasi Deret Peluruhan}

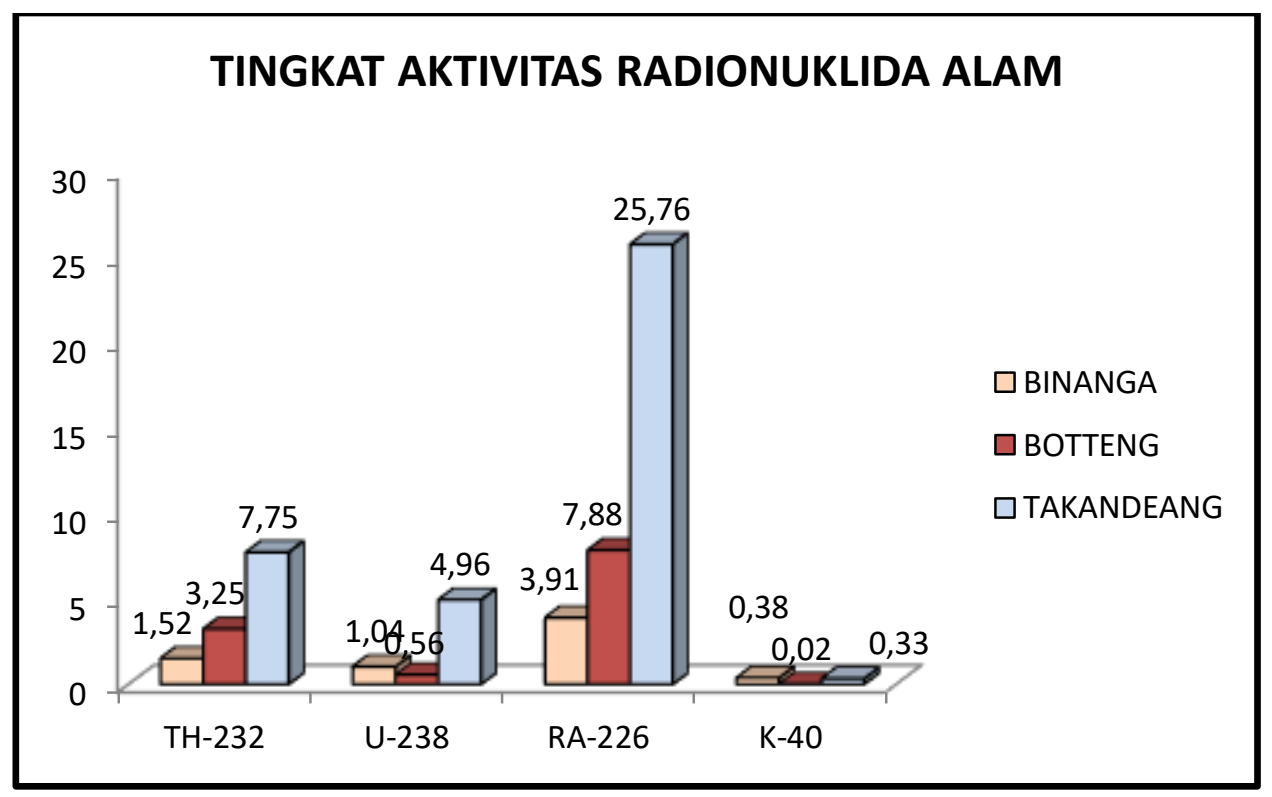

Gambar 2. Grafik aktivitas uranium, thorium, radium dan potasium.

Dari beberapa nuklida yang teridentifikasi dalam semua sampel, kita dapat mengelompokkan radionuklida tersebut dalam deret peluruhan Th-232 dan U-238 dimana U-235, Th-231 (termasuk deret peluruhan U-235, akan tetapi karena dalam setiap U-238 pasti terdapat U-235 sehingga U-235 dan Th-231 dimasukkan dalam deret U-238). Kemudian $\mathrm{Pb}-214, \mathrm{Bi}-214$ merupakan deret peluruhan dari U-238 sedangkan $\mathrm{Pb}-212$, Bi-212 dan Ac-228 merupakan deret peluruhan dari Th-232. Ra226 dan K-40.

Dan pada grafik 2 menunjukkan aktivitas total dari deret Uranium, Thorium, Potasium, dan Radium. Setelah dikelompokkan dan diperoleh hasil aktivitas total untuk radionuklida deret U-238 tertinggi terdapat di daerah Takandeang dengan aktivitas rata-rata adalah $4,96 \mathrm{~Bq} / \mathrm{g}$. Sedangkan untuk deret Th-232 aktivitas tertinggi dapat dilihat di daerah Takandeang dengan aktivitas rerata radionuklida mencapai 7,75 Bq/g. Data hasil aktivitas deret Th-232 ini sesuai dengan penelitian sebelumnya oleh Moekhamed Alfian PTKMR-BATAN (2016) yang menunjukkan aktivitas tertinggi berada di daerah Takandeang dan Botteng. Kemudian untuk Ra-226 yang terbaca pada sampel menunjukkan hasil aktivitas paling tinggi jika dibandingkan dengan nuklida lain dalam sampel. Untuk aktivitas Ra-226 aktivitas tertinggi ditemukan di daerah Takandeang dengan aktivitas sampel mencapai 25,76 Bq/g. Sedangkan nilai batas yang ditetapkan oleh BAPETEN dan IAEA adalah $1 \mathrm{~Bq} / \mathrm{g}$. Hasil pengukuran sudah sangat melampaui batas yang telah ditetapkan. Sedangkan untuk aktivitas K40 pada sampel memiliki aktivitas rata-rata yang tidak mencapai $1 \mathrm{~Bq} / \mathrm{g}$ dan masih di bawah batas normal yang aktivitasnya tidak mencapai nilai atas yang dikeluarkan oleh IAEA yaitu $10 \mathrm{~Bq} / \mathrm{g}$. 
Tabel 2. Konsentrasi aktivitas Radionuklida alam normal dalam material tanah TABLE 1-3: LEVEIS FOR CLEARANCE OF MATERLAL: ACTIVITY CONCENTRATIONS OF
RADIONUCLIDES OF NATURAL ORIGIN

\begin{tabular}{|c|c|}
\hline Radionuclide & Activity concentration $(\mathrm{Bq} / \mathrm{g})$ \\
\hline K-40 & 10 \\
\hline $\begin{array}{c}\text { Each radiounclide in the uranium and thorium } \\
\text { decay chains }\end{array}$ & 1 \\
\hline
\end{tabular}

Setelah kita mengelompokkan radionuklida dalam sampel maka kita bisa membandingkan konsentrasi deret U-238 dan Th-232 dari sampel dengan tabel konsentrasi radionuklida alam normal dalam material tanah yang diterbitkan oleh United Nation Scientific Committee on The Effect of Atomic Radiation (UNSCEAR).

Tabel 3. Konsentrasi radionuklida alam pada tanah di beberapa negara lain

\begin{tabular}{|c|c|c|c|c|c|c|c|c|c|}
\hline \multirow{3}{*}{ Reginaicruatry } & \multirow{3}{*}{$\begin{array}{l}\text { Aypulation } \\
\text { in 19\% (10) }\end{array}$} & \multicolumn{8}{|c|}{ Caecentration in wal (Bq/e). } \\
\hline & & \multicolumn{2}{|r|}{$K-40$} & \multicolumn{2}{|r|}{ 2-2SK } & \multicolumn{2}{|c|}{$\mathrm{Ka}-2 \mathrm{Min}$} & \multicolumn{2}{|c|}{$\mathbf{T h}-232$} \\
\hline & & Mean & Range & Mcan & Ranec & Mran & Range & Mcan & Rang: \\
\hline \multicolumn{10}{|l|}{ Africa } \\
\hline Alpcria & $2 x=8$ & 037 & nowh-1.15 & 013 & $\operatorname{exces}-0.11$ & anse & $6000-0.18$ & neas & $0.00-0.14$ \\
\hline Expt & $6+27$ & $0 x 2$ & ons-ans & 003 & $0.006-12$ & 0017 & $0006-0,0 \times 4$ & $\operatorname{cots}$ & ache-eom \\
\hline \multicolumn{10}{|l|}{ Noeth Amerio } \\
\hline Costa Ris & 350 & 0.14 & $000 \mathrm{x}-3 \mathrm{~s}$ & 0046 & ant1-a.s & atebs & $0.011-0.13$ & oot1 & acol-0.04 \\
\hline Unitad States of Ameriva & $2 n+4$ & 0.37 & a.to-a.so & onst & exo4-0.14 & aben & aon-0.16 & aces & $0.004-0.13$ \\
\hline $\begin{array}{c}\text { Sondh Amacrica } \\
\text { Argentina }\end{array}$ & 3522 & 0.55 & $0.580-750$ & & & & & & \\
\hline \multicolumn{10}{|l|}{ East Asia } \\
\hline Bangladesth & 1201 & 0.15 & a.3-ast & & & ag34 & ang1-0.043 & & \\
\hline China & 1212 & 0.44 & $000-1.80$ & $0 \times 3$ & $0 \times 08-0.60$ & $\operatorname{aes} 2$ & $\operatorname{son} 2-0.44$ & 0041 & $0 \times 04-0.6$ \\
\hline -Hoeg Koege SAR & 6.19 & 053 & $0.5-1.10$ & 0004 & aigea 13 & 0009 & a.060-0.11 & $\cos 5$ & aet6-ax \\
\hline India & 946 & $0,-\infty$ & ansenas & $002 y$ & ecot-0ast & anes & a.67-0.081 & 0004 & $0.014-0.16$ \\
\hline lapan & 225.4 & 0.31 & $0015-092$ & 0009 & exo-1.059 & $\operatorname{eng} 3$ & acob-0.09s & $\operatorname{anc} x$ & avis-oors \\
\hline Kirakthatan & 1689 & $0 \approx$ & $0.10-1.20$ & 0037 & $0012-012$ & 0.035 & $0012-0.12$ & exo & aeto-e.n2 \\
\hline Koecia, Repe of & 2531 & ast & $0.017-130$ & & & & & & \\
\hline Malayia & 20.58 & 0.31 & $0.17-0.43$ & a.res & อ.649-0osh & 0.057 & a038-0004 & $\operatorname{sen} 2$ & ans-a.11 \\
\hline Toiland & $5 \times 70$ & 0.23 & 6.00t-a72. & 0.114 & a.ces-a.37 & 0.048 & อ.11-6.07s & a.esi & $\operatorname{acos}-a_{12}$ \\
\hline
\end{tabular}

Dari tabel diatas menunjukkan konsetrasi radionuklida alam dalam tanah untuk deret K-40 di tanah Mamuju masih dalam rerata yang hampir sama dengan negara-negara yang ada dalam tabel tersebut. Yaitu sekitar $0,38 \mathrm{~Bq} / \mathrm{g}$. Sedangkan untuk deret U-238 dalam sampel berada pada range 1,57-11,4 Bq/g. Sedangkan di negara-negara lain menunjukkan aktivitas berada pada range yang tidak mencapai 1. Begitu pula untuk deret Th-232 menunjukkan aktivitas radionuklida pada range $4,18-13,07 \mathrm{~Bq} / \mathrm{g}$. Sedangkan dalam tabel aktivitas tanah di negara lain tidak ada satupun negara yang menunjukkan untuk deret Th-232 mencapai pada range 1 
$\mathrm{Bq} / \mathrm{g}$. Dan untuk Ra-226 menunjukkan konsetrasi yang sangat tinggi jika dibandingkan dengan negara lain, yaitu tertinggi $25,76 \mathrm{~Bq} / \mathrm{g}$.

\section{KESIMPULAN}

Berdasarkan hasil penelitian maka dapat disimpulkan bahwa:

1. Pada pengukuran dengan menggunakan LBC (Low Background Counter) hasil pengukuran menunjukkan adanya aktivitas yang cukup tinggi dari ketiga sampel yang telah diukur. Aktivitas tertinggi berada di daerah Takandeang dengan nilai aktivitas mencapai $12,59 \mathrm{~Bq} / \mathrm{g}$. Kemudian di daerah Binanga aktivitas mencapai $2,96 \mathrm{~Bq} / \mathrm{g}$ dan di daerah Botteng aktivitas tanah mencapai 2,62 Bq/g. Jika dibandingkan dengan data pengukuran LBC oleh PSTA-BATAN aktivitas tanah di daerah Yogyakarta menunjukkan aktivitas tanah tidak mencapai $1 \mathrm{~Bq} / \mathrm{g}$. hal ini dapat membuktikan bahwa adanya nilai aktivitas yang cukup signifikan jika dibandingkan dengan data hasil pengukuran yang diperoleh di daerah Mamuju.

2. Pada pengukuran dengan menggunakan Spektrometer Gamma, hasil pengukuran menunjukkan aktivitas radionuklida tanah yang sangat tinggi dari ketiga sampel. Aktivitas radionuklida tertinggi berada di daerah Takandeang dengan aktivitas total mencapai $8,03 \mathrm{~Bq} / \mathrm{g}$. Botteng 2,41 Bq/g. dan Binanga 1,5 $\mathrm{Bq} / \mathrm{g}$. Sedangkan batas yang diizinkan untuk radionuklida alam deret Uranium dan Thorium berdasarkan IAEA adalah $1 \mathrm{~Bq} / \mathrm{gram}$. Hasil aktivitas yang tinggi dari ketiga sampel menunjukkan adanya kandungan radionuklida alam yaitu Uranium dan Thorium

3. Aktivitas pada sampel telah melampaui batas normal yang telah ditetapkan oleh IAEA (International of Atomic Energy Agency) Yaitu $1 \mathrm{~Bq} / \mathrm{g}$. Sedangkan untuk K40 masih dibawah batas konsentrasi yaitu $10 \mathrm{~Bq} / \mathrm{g}$. Untuk itu perlu adanya pengawasan yang lebih lanjut dari pihak yang berwenang dalam hal ini BAPETEN.

DAFTAR PUSTAKA

A.Zubaidah,YantiLusianti,dkk.2012.Respon Sitogenik Penduduk Daerah Radiasi Alam di Kabupaten Mamuju Sulawesi Barat.Jogyakarta: BATAN

Alfiyan,Moakhamad.2016. Tantangan Pengawasan Naturally Occuring Radiactive Material (NORM) di Kabupaten Mamuju. Yogyakarta: BATAN

E.Martin,James.2013.Physics for raduiation Protection.Third Edition.Weinhem: WILLEY-VCH GmbH\&Co.KGaA

IAEA,2011. Radiation protection and safety of radiation sources : international basic safety standards: general safety requirements-Interim edition. Vienna : International Atomic Energy Agency

Tenrimaya,anisa,dkk. 2015. Pengukuran Konsetrasi Gas Thoron di Udara. Jakarta :BATAN

Wahyuningsih, Sry.Siswanti.2010. Pengukuran Radioaktif Beta Total Pada Sampel Tanah Di Kawasan Reaktor Nuklir Kartini Tahun 2010. Yogyakarta : BATAN 